\title{
150 years after Morrill Act, land-grant universities are key to healthy California
}

$\mathrm{T}$ his issue of California Agriculture explores a range of topics representing the breadth of scientific expertise and focused inquiry found across UC Agriculture and Natural Resources (ANR). It explores new business models for direct marketing, targeted nutrition research, genetic resistance to plant disease, biological control of pests and improved production methods for California's strawberry industry. These are clear examples of the legacy of research and innovation documented in the journal's 66-year history.

President Abraham Lincoln signed the Morrill Act into law 150 years ago, launching publicly supported landgrant institutions nationwide - including the University of California. President Lincoln and those who wrote and supported the legislation had a revolutionary vision of accessible and affordable higher education that would advance our nation's agricultural and industrial knowledge and expertise. Their imagination and foresight led to a system that remains unique in the world. There can be no question that this system has been critical to the growth of our nation and what is, for now, the world's largest economy. We are no less certain that UC, and ANR's outstanding scientists and educators, have been essential to the development of California's dynamic food system, our rich natural resources and our youth and families.

In 2014, we will celebrate the centennial of the signing of the Smith-Lever Act, establishing Cooperative Extension in partnership with the land-grant universities and their Agricultural Experiment Stations. This Act enabled an equally original vision of a continuum of scientists discovering and delivering research-based information to solve local and global problems and contributing to the growth of California's world-leading agricultural economy dedicated to healthy food systems, environments, communities and Californians.

Since assuming the role of ANR vice president, I am even more convinced that these revolutionary visions and landmark pieces of legislation, and the challenges and opportunities described in our Strategic Vision 2025

(http://ucanr.org/About_ANR/Strategic_Vision) are important, necessary and compelling.

As I write, UC again finds itself at the center of a fundamental and passionate discussion about the future of public investment in higher education and the system of universities that conduct research, extend science-based solutions, and educate professionals and scientists whose innovation and entrepreneurship support the benefits we all enjoy. All partners in the ANR community are affected by these issues.

Both human- and financial-resource issues present a daunting array of obstacles and an exciting set of difficult choices. Meanwhile, the contributions of our academics and staff continue to demonstrate an unmatched body of creative and relevant inquiry and a commitment to extending that knowledge in the form of practical solutions and critical feedback.

Our near-term and strategic goals are to ensure that all elements of the community thrive and that we act swiftly and effectively to support and focus the extraordinary resources of our people to solve critical issues and address complicated problems. Guided by our Strategic Vision, we have taken important steps:

- Launched five strategic initiatives.

- Begun critical academic recruitments.

- Completed our first round of competitive grants.

- Captured significant administrative efficiencies.

- Enhanced statewide program leadership.

- Expanded consultation and leadership interactions.

- Focused our communications, both internal and external. Much more remains to be done. We are increasing efforts to: (1) engage with key external stakeholder groups and leaders; (2) increase proactive communications and active responses to critical issues, focusing on solutions and relevant research; (3) restructure our county partner relationships to improve program delivery and operate more efficiently; (4) develop improved collaborative processes for recruiting extension specialists and advisors; (5) efficiently support program planning and multidisciplinary interactions; and (6) improve the support structure for UC ANR academics.

We have taken many steps toward achieving our Strategic Vision in the past 4 years, despite the fact that we are operating with reduced resources and the loss of expertise in critical areas as many academics retire. Meanwhile, an array of issues evolve and develop with profound implications for California's agriculture, natural resources and communities.

We must acknowledge that we face real constraints in people, resources and time, which make it even more critical to work together. While we continue to look for more efficient ways operate, we must promise only what we can deliver and deliver all that we promise. The opportunities to discover and implement science-based solutions and make a real difference are only enhanced by close collaborations and a shared vision in our various units of ANR.

In spite of all the hurdles we face, as a community we enjoy amazing and unmatched academic talent and a dedicated and involved staff. As we recruit new academics, carefully focus our resources and move to address critical issues, I believe that a thriving UC ANR community will help renew and reinvent the vision of President Lincoln, Justin Smith Morrill and others. I am committed to continuing the work of those who have realized that vision to the benefit of us all and to demonstrating our commitment to excellence in research, problem-solving and public service. 